\section{Domestic violence and abuse in intimate relationship from public health perspective}

\author{
Zlatka Rakovec-Felser \\ Department for Health Psychology \\ Faculty of Medicine, University of \\ Maribor, Slovenia
}

\begin{abstract}
In this article we pay attention to the violence which, due to the fear of social stigma, could be hidden from the public eye for a long time but could have serious health consequences for the individual, family, and society - physical and psychological forms of domestic violence and abuse in male-female intimate relationship. Besides its nature and extent data in general population, we review also the surveys data about its theoretical basis, its risk factors and possible effects on mental and physical health, not only on in conflicts involved partners, but also on family as a whole, and especially on the children that growing up in such a problematic domestic circumstances.
\end{abstract}

\section{Introduction}

The APA Task Force on Violence and the Family defined domestic violence as pattern of abusive behaviors including a wide range of physical, sexual, and psychological maltreatment used by one person in an intimate relationship against another to gain power unfairly or maintain that person's misuse of power, control, and authority. It can either results or has a high likelihood of resulting in injury, psychological harm, mal-development, or even a death. Walker points that when one form of family violence appears, we can expect all others, including various aggressive acts outside the family, in community. 1

Huss defined the nature of domestic violence as any action of violence perpetrated within the context of significant interpersonal relationship. Domestic violence could include violence between a husband and a wife, a girlfriend and boyfriend, or gay or lesbian partners. It could be violence between parents and children, adult children and elderly parents, or we could meet it between siblings. ${ }^{2}$ Krug et al. have addressed similar topics. They said that intimate partnership abuse can be found in all relationships, both same-sex and heterosexual. ${ }^{3}$ But although domestic violence can take place in any intimate relationship, the great majority of it is perpetrated by men against women and makes because of its frequency and severity a much larger problem in public health terms. ${ }^{4}$

Walker notes that term violence and abuse was found to be used differently. The original terms in USA studies to identify domestic violence include wife abuse, woman abuse, battered women, and partner abuse. Author also exposes that when the physical, sexual and psychological abuse that usually, although not exclusively, is directed against women partners, it is talk in term of domestic violence and abuse, while in the same case when it is directed against children the term child abuse is used much more than domestic violence.

\section{The extent and nature of domestic violence and abuse}

As domestic violence cases increasingly enter the court system, and consequences of aggressive accidents threaten the functioning, well-being and health of victims, in family or outside systems, it is important to describe extent and nature of this phenomenon. ${ }^{2}$ Although both men and women initiate violence, the violence enforced by women is less frequently and has less severe consequences compared to male offenders. 5 Straus and Gelles, using the National Family Violence Survey found that the injury rate for women was 6 times higher than for men. ${ }^{6}$ Worldwide, 10-50 per cent of women report having been hit or physically assaulted by an intimate partner at some time in their lives. ${ }^{4}$ Some estimates suggest that as many as one-third of all women are victims of domestic violence during their lifetime.2 Four million women each year are assaulted by a domestic partner. ${ }^{7}$ For those aged from 18 to 59 around one in four women and one in eight men reported experiencing partner abuse in year 2008 to $2009 .{ }^{8}$ Woman's pregnancy is high-risk period for the initiation and escalation of intimate partnership violence, and is leading cause of maternal mortality in the UK, USA and Australia. ${ }^{4}$ Same risk period for the outbreak of violence against women in intimate partner relationship was also found in research of Jasinski and Kantor. Another period that is especially dangerous for women is at the ending of relationship because their partners become threatened by a clear indication of a change or loss in the relationship. ${ }^{2}$ It could occur in all social strata, but there is some evidence of population disparities, across socio-economic and ethnic groups, and particular a higher prevalence for learning-disabled people. Cooper et al. note that about 5.6 per cent of older couples reported physical violence in their relationship in the past year and that for vulnerable elders
Correspondence: Zlatka Rakovec-Felser, Department for Health Psychology Faculty of Medicine, University of Maribor, Slomškov trg 15, 2000 Maribor, Slovenia.

Tel.: +386.223.55280 - Fax: +386.223.55211

E-mail: zlatka.rakovec-felser@triera.net

Key words: domestic violence, perpetrator, victim, gender differences.

Conflict of interests: the authors declare no potential conflict of interests.

Received for publication: 10 July 2014.

Revision received: 9 September 2014.

Accepted for publication: 14 September 2014.

This work is licensed under a Creative Commons Attribution NonCommercial 3.0 License (CC BYNC 3.0).

(C) Copyright Z. Rakovec-Felser, 2014

Licensee PAGEPress, Italy

Health Psychology Research 2014; 2:1821

doi:10.4081/hpr.2014.1821

(dependent on a carer, disabled) rates were much higher, with nearly 25 per cent reporting significant abuse. 4

A common pattern of domestic abuse, especially this between intimate partners, is that the perpetrator alternates between violent, abusive and apologetic behavior with apparently heartfelt promises to change and that the abuser could very pleasant most of the time.

Walker $(1970,1984,1999)$ developed, on the basis of social cycle theory and Seligman's phenomenon of learned helplessness, the theory of cyclic abuse with a hypothesis that abusive relationships, once established, are characterized by a predictable repetitious pattern of abuse. She suggested that sustained periods of living in such a cycle may lead victim to learned helplessness. Abuse Cycle is known also as a Battered Women Syndrome which consists of these symptoms: re-experiencing the battering as if it were recurring even when it is not; attempts to avoid the psychological impact of battering by avoiding activities, people, and emotions; hyper arousal or hyper vigilance; disrupted interpersonal relationships; body image distortion or other somatic concerns; sexuality and intimacy issues.1,9 But feelings of depression and woman passivity may be also a result of lack of support in environment. Gondolf and Fisher found that women in abusive situations shown increase more help-seeking behavior as acts of violence against them intensified. However, their attempts to find help and protection outside family could be frustrated because on her appeals arrive no responds. ${ }^{10}$ In a 2002 study, Gondolf found that more than half of women had negative views of shelters and programs 
for battered women because of negative experiences with those programs. ${ }^{11}$

Abuse is rarely constant but alternates between four stages: i) period of tension building (tension starts and steadily builds, abuser starts to get angry, communication breaks down, victim feels the need to concede to the abuser, tension becomes too much, victim feels uneasy); ii) acting out period (any type of abuse occurs); iii) the honeymoon period (abuser apologizes for abuse, some beg forgiveness or show sorrows, abuser may promise it will never happen again, blames victim for provoking the abuse or denies abuse occurred, minimizing); iv) the calm period (abuse stops, abuser acts like the abuse never happened, promises made during honeymoon stage may be met, abuser may give gifts to victim, victim believes or wants to believe that the abuse is over or that the abuser will change).

In fact, such a behavior pattern explains why for the most victims it is so difficult to break their exhausting relationship. Due to perpetrator's acts of apologies and loving gestures between the episodes of abuse, they are ready to believe that partner's violent and abusive practice will really never appear again. But on the other hand, it is also not so simple if a battered woman decides to stop her relationship. Research data pointed out that leaving the relation with the partner often does not stop the abuse. Many perpetrators continue to harass, stalk, and harm the victim long after she has left him, sometimes even resulting in someone's death. In one U.S. study, 70 per cent of reported injuries from domestic violence ocuured after the separation of couple. ${ }^{1}$

\section{Theoretical perspectives of domestic violence and abuse}

There are three broad theoretical approaches explaining the phenomenon of domestic violence: feminist, conflict, and social learning theories. Feminist theory argues that wife abuse is directly connected to the patriarchal organization of society, which is reflected in the pattern of behaviors and attitudes toward women. ${ }^{12,13}$ In addition, masculinity is often characterized as being authoritative and controlling of women. A feminist approach emphasizes the significance of gender inequality and contends that it is a major factor in malefemale violence. Violence and abuse are viewed as an expression of social power and become used as a way of men to control and dominate their female partners. Men could resort to aggressive forms of control over women particularly when they experience powerlessness. ${ }^{14}$ Important social institutions have tolerated the use of physical violence by men against women in the past. The patriar- chal arrangement of families, ideals of masculinity, and a cultural acceptance of the use of force to gain control over others, all create and also foster a social environment for wife abuse and other forms of family violence. 15 While feminist theory describes the patriarchal nature of family and society, conflict theoretical approach exposes family and society as a place involving a conflict between their members and their divergent interests. ${ }^{16}$ When different interests produce conflicts, aggression and violence are the way that individuals may utilize to resolve the situation in their favor, particularly when other strategies fail. ${ }^{17}$

This theoretical approach could be helpful especially in explaining the causes of violence between siblings. A conflict between siblings is often believed to be driven by jealous rivalry with siblings competing for parental attention and affection. The study of adults revealed that two thirds of them perceived their siblings as rivals during childhood, and perpetrators of sibling violence may be driven by feeling of powerlessness brought on by favoritism. 14

The feminist and conflict perspectives address social structural condition in society and family, whereas social learning theory provides an explanation for family interaction patterns that foster violence and abuse. It contends that behavior is learned in large part through observation, imitation, and reinforcement. Prior to engaging in an observed behavior, an individual generates ideas about probable rewards and punishments. Reactions from others are used to develop implicit rules that are applied to future in similar situation. As a result, learning often occurs through direct experience, with individuals learning guidelines for many behavior forms that are more complex than the specific action observed. ${ }^{14}$ So, aggressive behavior is adopted as a response because direct and indirect experience suggests that the desired rewards, not negative sanctions, will be the anticipated outcome or reaction from others. Consequently, modeling and reinforcement are two of the most important processes in learning aggressive behavior. ${ }^{18,19}$

Individuals with intimate and frequent contacts, and those with higher social power, are the most likely to be observed and imitated. Consequently, learning often occurs through interactions with significant others. Children are more likely to imitate when they strongly identify with person, when this person is familiar and demonstrates approval. ${ }^{14}$ Bandura also found that when adult males performing aggressive acts were more likely to be modeled by children, and he found also that familiarity much more influenced boys than girls. ${ }^{18,19}$ If a father uses aggressive behavior against his wife or child with successful results, children, particularly sons, are more likely to model this behavior with siblings. ${ }^{20}$

\section{The risk factors of domestic violence and abuse}

\section{The perpetrators}

In context of the domestic violence in intimate partner relationship between men and women the oldest and still widely adopted perspective is psychological based. It focus on personality disorders and early experiences that increase the risk of violent behaviour. ${ }^{21}$ Moffitt et al. report that while men exhibit more aggression overall, gender is not a reliable predictor of interpersonal aggression, including psychological aggression. Their study found that whether male or female, aggressive people share a cluster of traits, including high rates of suspicion and jealousy, sudden and drastic mood swings, poor self-control, and higher than average rates of approval of violence and aggression. They also argue that antisocial men exhibit two distinct types of interpersonal aggression: against strangers, and against intimate female partners, while antisocial women are rarely aggressive against anyone other than intimate male partners. ${ }^{22}$ Dutton and Bodnarchuk, Carney and Buttell, and Henning and Feder reported that male and female perpetrators of emotional and physical abuse exhibit high rates of personality disorders. ${ }^{23-25}$ Studies have found incidence rates of personality disorders to be $80-90$ per cent in both court-referred and self referred wife assaulters, compared to estimates in the general population, which tend from 15-20 per cent. ${ }^{23}$ As the violence becomes more severe and chronic, the like hood of psychopathology in these men approaches 100 per cent reported Hart, Dutton, and Newlove, and Dutton and Hart. ${ }^{26-28}$ But Gelles stated that only 10 per cent of violently incidents might be labeled as primary caused by mental ill persons, whereas 90 per cent are not amenable to merely psychopathological explanations. It should be noted that many personality dysfunctions, for example low impulse control, are not considered pathological but rather a personality disorder. ${ }^{6}$

Dutton (1988) argued that three specific forms of personality disorders were prevalent among wife assaulters: antisocial, borderline and over-controlled. In series of studies he described associated psychological features of abusiveness that clustered around Oldham et al. measure of Borderline Personality Organization: shame-based rage, a tendency to project blame, attachment anxiety manifested as rage, and sustained rageful outbursts, primary in intimate relationships.

Profile of an abuser correlate with the Cluster B personality disorders: Anti-Social Personality (a pervasive pattern of disregard for and violation of the rights of others, lack of empathy), Borderline Personality (a pervasive 
pattern of instability in relationships, selfimage, identity, behavior and affects often leading to self-harm and impulsivity), and Narcissistic Personality (a pervasive pattern of grandiosity need for admiration, and a lack of empathy).

These disorders display characteristics that involve grandiose delusions and a self inflated sense of importance which are critical behaviors for an abuser to have in order to maintain strict and severe control over their victim. The abuser also needs to have a very low affect and low sense of empathy so that they do not have remorse for the abuse and actions they are inflicting on their victim. All of these qualities are characteristics found on the Axis II disorders in the DSM-IV. 23

Abusers may aim to avoid household chores or exercise total control of family finances. They can be manipulative, often recruiting friends, law officers and court officials, even the victim's family to their side, while shifting blame to the victim. They deny the violence and abuse or rationalize it and tend to use such types of defenses: total outright denial (It never happened. You are just imagining it. You want to hurt me), alloplastic defense (It was your fault, your behavior provoked me into such reactions), altruistic defense (I did it for you, in your best interests!), transformative defense (What I did to you, it was common and accepted behavior).

Perpetrators are usually concerned with their reputation and image in the community - among neighbors, colleagues, co-workers, bosses, friends, extended family, and therefore they use in the public the specific forms of denial: family honor stricture (We don't do dirty laundry publicly, the family's honor and repute must be preserved, what will the neighbors say?), and family function stricture (If you snitch and inform the authorities, they will take me away, and the whole family will be disintegrate). ${ }^{29,30}$

\section{The victims}

The victims of violence and abuse in intimate relationship between man and woman can be found in all social and economic classes and can be wealthy, educated, and prominent as well as undereducated and financially destitute. They live in rural areas, urban cities, subsidized housing projects, and in gated communities. In general, domestic violence affected largely women, children of both sexes, but men are also raped and experience domestic violence. 4

The fact that the victim could be a male partner is confirmed by recent research. On the delusion that arises around this question inside our heads have recently exposed Dutton and White: The stereotype invoked when one mentions domestic violence is a bulling, domineering man who is hyper-reactive to jealousy and has a drinking problem. And to continue: The gender paradigm stereotype also holds that female violence is less serious, only what Johnson calls common couple violence. In fact, the data again say something else. It was simply that easier research was driven by paradigm that avoided asking the right question of men. When these questions are asked, the results are surprising.

An emergency clinic in Philadelphia found that 12,6 per cent of all male patients over thirteen week period were victims of domestic violence. ${ }^{31}$ Same results also reported Hines and Douglas. ${ }^{32}$ Authors Williams and Frieze agree that terms of battered women do not explain all of the patterns of violence that occur in couples. Data from their research shown that women can be equally violent or display even more frequent violent acts than men toward partners: 21.6 per cent victims were male, 28.7 per cent victims were women, bilateral violent and abusive were 49 per cent of couples. They considered that many study in the past were based only on women's reports. ${ }^{33}$ Brown and also Henning and Renauer found that men compared to female offenders were likely to be arrested. They are also treated more harshly by criminal justice system. Brown found that in case where only the male partner was injured, the female was charged in 60.2 per cent of the cases, however, when the female partner was injured, the male was charged 91.1 per cent of the time. In no-injury cases, the male was charged 52.5 per cent of the time, the female 13.2 per cent of the time. Brown also found that women were more likely to have used weapons and caused injuries and also to have received more serious charges (more than twice as likely to be charged with aggravated assault or assault with a weapon), and that those who were prosecuted tended to have inflicted higher levels of injury against their victim than prosecuted men and, as with arrested women, were more likely than men to have used weapons. In severe injury cases, 71.4 per cent of men and 22.2 per cent of women were found guilty. The low percentage of women found guilty was due to witness problems (few men being willing to testify). ${ }^{34}$ Fontes believes that men have more difficulty in expressing their hardship if they are victims of violence. He identifies several reasons and one of them is dilemma because they are socialized to be strong, physically and emotionally, to be provider, especially women and children. So they are early trained to suppress their fear and pain and have later difficulty in expressing emotions because they are aware that patriarchal society and men in general do not want view males as victims (to be vulnerable, to be weak, to be unmanly because it means be a wimp). Other reasons he found in feminism and gender politics. Even if a man decides that he wants support, he often doesn't have such a social networks as a woman and cannot so easily complain, what is happening to him. In practice, he can also be afraid that if he was to report his wife to the police, the police would not take his allegation seriously. 35

\section{The family violence theories}

The family is a major socializing institution and a likely context for relatively high level of aggression. Many researchers have found a link between childhood experiences of aggression behind the domestic walls and violence and abuse in adulthood. Phenomenon was called as intergenerational transmission of violence. Important part of such process is learning through modeling. Social learn theory suggests that a child learns not only how to commit violence but also learns positive attitudes about violence when he/she sees it rewarded. So he/she learns destructive conflict resolution as also patterns of interpersonal communication. ${ }^{36}$ However, the Theory of Intergenerational Transmission of Violence provokes some criticism and opens several questions. One is in the potential different effects of experiencing aggression during childhood. Another element of complexity lies in whether one who grows up in a violent home is at risk for becoming a perpetrator or a victim of spouse abuse as some studies have provided empirical support for the notion that growing up in an aggressive family increases the probability of being a victim of spouse abuse, whereas other studies have provided support for the notion that growing up in an aggressive home increases the probability of being a perpetrator of spouse abuse. A third element of complexity relates to gender. Recently, theorists have suggested that the intergenerational transmission of violence may operate differently for men and women. The need for a gender sensitive application of the intergenerational transmission of violence theory has been supported empirically in a number of studies. Contradictory findings have emerged from gender-sensitive research examining the intergenerational transmission of marital aggression. ${ }^{37}$

\section{The impact of domestic violence and abuse}

Certain, the violence, and abuse have not positive effects in both cases, if the victim of violence and abuse in intimate relationship is a woman or a man. According to the surveys data that women victims predominate, it is expected that much more researches verify the relationships between women's health and their violently experiences compared to those which study health consequences by the male victims. 
Intimate partnership violence and battering as its frequently part, has specific, long-term negative health consequences for victims, even after the abuse has ended. Battering is meant as repeated physical or sexual assault within a context of coercive control and emotional abuse as it's frequently part. Measures of the coercive control include verbal threats, financial control, emotional abuse, sexual abuse, and threats against the children, belongings, or pets. Negative effects can manifest as poor health status, poor quality of life, and high use of health services. ${ }^{38}$ Orem, author of Self Care Deficit Theory, whose central concept of self care agency is defined as individuals' ability to engage in self care, considers the battering as a threat to one of the identified universal self care requisites, prevention of hazards to life, functioning, and well-being. The model importantly includes as outcomes a women's physical as well psychological health. ${ }^{39}$

Battering is a significant direct and indirect risk factor for various physical health problems frequently seen in health-care settings and is one of the most common causes of injury in women. ${ }^{40}$ Plichta states that intimate partner violence and abuse is associated with increased mortality, injury and disability, worse health status, chronic pain, substance abuse, reproductive disorders, and proper pregnancy outcomes. It is also associated with overuse of health services. ${ }^{41}$ Campbell indicates the fact that 40-60 per cent of murders of women in the USA perpetrated by their intimate partners. Battering in intimate partnership violence is also one of the most common causes of injury in women. An injuries, fear, and stress can result in chronic health problems as chronic pain by headache, back pain. ${ }^{42}$ It was also found that battered women have significantly more than average self-reported gastrointestinal symptoms and diagnosed functional gastrointestinal disorders. This was found also as past, in childhood experiencing sexual abuse, or both. 43 Gynecological problems, among them chronic pelvic pain and urinary-tract infections, are the most consistent, long lasting, and largest physical health difference between battered and non-battered women. The combination of physical and sexual abuse that characterizes at least $40-45$ per cent group of battered women puts these women at an even higher risk for health problems than women only physical assaulted. 40 It was also found that experiencing psychological intimate partner violence is associated with significant increase in risk of development such conditions: disabilities preventing work, chronic neck or back pain, arthritis, migraines or other frequent headaches, stammer or stutter, problem seeing with glasses, chronic pelvic pain, transmitted infections, stomach ulcers, spastic colon, indigestion, constipation, and diarrhea. Psychological intimate partner violence was defined as woman's constantly feeling of susceptibility to danger, loss of power and control, and entrapment. Physical intimate partner violence was found to be correlated to hearing loss, angina, with cardiovascular problems, gastric reflux, and bladder or kidney infections. ${ }^{44}$

Others' evidence suggests that women who are exposed to violence by their partners show also psychological consequences: higher level of depression, anxiety and phobias than nonabused women. It was found also higher level of emotional distress, thoughts, or attempts of suicide among women who had ever experienced physical or sexual violence than those who had not. In addition, intimate partnership violence has also been linked with: alcohol and drug abuse, eating and sleep disorders, physical inactivity, a poor self-esteem, a post-traumatic stress disorder, smoking, self-harm, unsafe sexual behavior, the increased exposure to injuries. ${ }^{41}$ Golding found that in 11 studies examining the prevalence of posttraumatic stress disorders among victims of domestic violence 63.8 per cent women suffered from it. His meta analysis also found that 18.5 per cent battered women experienced alcohol abuse and 8.9 per cent of them suffered from drug abuse. ${ }^{45}$ Stark and Flitcraft estimated that battered women were at five times greater risk for a suicide attempt than women who were not in abusive relationship. ${ }^{46}$ Furthermore, to the both physical and psychological abuse is related also lowered selfesteem as found many researchers, among them Aguilar and Nightingale. ${ }^{77}$ 0'Leary concluded that psychological abuse has more severe long term psychological effects than physical abuse and that the psychological abuse normally occurs prior to the physical abuse. At this point it should be noted that different authors mention slightly different major forms of psychological abusive behavior. Sacket and Saunders submit four major forms including criticizing behavior, ridiculing personal traits, jealous control behavioral pattern, and ignoring while Murphy and Cascardi proposed four factor model which include hostile withdrawal, domination/intimidation, denigration, and restrictive engulfment. ${ }^{48,49}$ Even victims believe that the psychological abuse is more damaging to them found Follinstad, Rutledge, Berg, and Hause.50

But, domestic and intimate violence and abuse are not traumatic only for adults in a family. Osofsky notes that several studies have found that $60-75$ per cent families in which a woman is battered, children are also battered. She presents also his research data and states that in homes where domestic violence occur children are physically abused and neglected at the rate 15 times higher than is national average. She mentions some authors who identify adverse effects on children's physical, cognitive, emotional, and social development. Existing researches show association between child exposure to violence and his/her emotional and behavioral disorders, even for this in the earliest phase of development. Such children are excessive irritable, show immature behavior patterns, sleep disturbances, emotional distress, fears of being alone and regression in toiling and language. Exposure to violence in family interferes with child's normal development of trust and later exploratory behavior, which lead to autonomy. 51

Both experiencing and witnessing domestic violence produced in children symptoms of posttraumatic stress disorders and reduces the sense of security. Campbell and Lewandowski cite the research results of Slusi, who has been found that violence becomes traumatic when victim does not have ability to consent or dissent and are passive observer with feeling of helplessness and hopelessness. They also highlight the research of Mc Closky et al., who have found that many children of battered women aged 6 to 12 had observed their mother being choked, threaded with weapon, or threaded with death in other way and noted that those children were living under the shadow of lethal threat. They note Terr's conclusions that traumatized children response to violence and abuse with: strongly visualized or otherwise repeatedly perceived memories; repetitive play or behavior enactments of trauma; trauma specific fears as well as fears of mundane things (the dark or certain animals); changed attitudes about people, life, and future.

Later controlled studies indicated cognitive and emotional responses such as higher level of internalizing (anxiety, social withdrawal, depression), fewer interests and social activities, preoccupation with physical aggression, withdrawal and suicidal ideation; behavioral disorders (aggressiveness, hyperactivity, conduct problems), reduced social competence, school problems, truancy, bulling, excessive screaming, clinging behaviors, speech disorders; physical symptoms (headache, bed wetting, disturbed sleeping, vomiting, failure to thrive, diarrhea). ${ }^{38}$

\section{Discussion}

After a brief overview of the wide range of research data about the theoretical basis of the violence and abuse in intimate relationships, its extent, forms of occurrence, causes, and consequences, the series of questions appears. What is in a relationship between the sexes change? Especially, as we know, that violence in relationship between men and women has 
always existed, and has been well evidenced by many literary works in the past from the ancient Greek tragedies forward? Have the traditional gender roles significantly altered and imbalance of power and control in relationship produces new sources of tension between men and women? Or is a just now possible to express experience, which has been previously strictly retained behind domestic walls? Is its extent and severity actually in increase, and it raised in modern society from a complex of factor interactions?

Domestic violence which consequences can affect quality of life not only of both participants, but also their children, and the elderly parents, if they living with them, enter today not only in schools, police, health and social care services, but also in criminal justice system. Due to consequently high costs and unfavorable economic effects they have been declared as a political problem which demands appropriate solutions. But, despite that the intimate partnership violence and abuse become today a major public health problem and one of the most widespread violators of the human rights, some found that this problem is still under-acknowledged in all European countries, as it is throughout the world.

The fact is that the research data of violence and abuse between men and women sometimes differ, often because still various basic approaches and the way the data has been obtained. But on the other side just this could contribute to the more complex understanding phenomenon perception, too. More problematic is, according to my observations, the integration this knowledge into everyday practice, particularly to those who are responsible and are first instance to detect problems in the family, assess the level of a risk, form a plan of protection and support, and implement it in the appropriate measures.

Let us highlight two problems: in the public services mostly overlooked psychological violence, and the sex of the victim, which should be to the common belief particular female. First, the psychological violence is undoubtedly a complex, multifactorial construct (also named psychological abuse, psychological maltreatment, verbal abuse, mental abuse, emotional abuse, or maltreatment) and it must be, as 0'Leary points, estimated as variable deserving critical attention. The fact is that its conceptualization, classification, and methodological issues is complex and we should take in to account not only the recipient of abusive behaviors and his/her perspective, but also the other side, perspective of initiator, moreover also observers' views, outcome of the actions, analysis of contextual variables, as well as analysis of the recipient's and initiator's views - not only in science, but also in treatment the persons presenting themselves as the victims of violence. Because of the various abusive strategies of perpetrator and their specific effects on victim's quality of life, physical and mental health, and last but not least on his/her self-esteem, the victim usually difficult promptly recognize partner's abusive behavior as such, and therefore are also not able to express it soon. In such a situation can be of great help right a sensible, well-educated professional person.

Second problem is public widespread belief that draws attention and calls for a rethinking about stereotypes that partner violence is an almost uniquely male and that when men assault their partner, it is primary to dominate women, whereas violence, perpetrated by women is always an act of self-defense or an act of desperation in response to male dominance and cruelty. It is suggested that such limitations in mind known also as gender paradigm, should be replaced. Fontes points out that only $1-2 \%$ of men who are assaulted by their female partners are likely to report the abuse to the police or outside agency, but it does not mean that men would not be in distress, and suffered from violence. This could confirm also by my own experiences of an expert witness. Perpetrators of domestic violence at the police and in court in fact are predominantly men and those who have decided to first break the wall of silence are usually women and not other side. Men extremely rare seek for help and ask protection from female violence, but if they do it, they soon leave the treatment, dissatisfied that there have not been well understood. They are confronted with social services and their professionals usually after their female partners have been lodged there a complaint against them. On this basis someone even be able to conclude that women more easily adopted a position of powerlessness, are able to ask for help, usually better articulate their crisis, and are also more impressive in their role as victims than other side. Some concrete examples speak for the fact that the one-side reports could be accepted, particularly because belief that in the role of victim could appear only a woman. Such situation can get serious proportions for man's quality of live when his former wife, supported by own network of advisors and encouraged also by institutional support, decides to accuse him of sexual child abuse. In case of ex-wives false profess for a man begins a long battle as this at windmills. Still in the first phase, at hearings at police and social care services, he can be considered as offender and he could collected and submitted papers to passed with attributed guilt, but nobody reads them exactly, so as he could find credible witnesses, but no one really listen to them. But what is most worrying, an acceptance of one-side reports could have serious consequences not only to the man's quality of life, even more serious consequences usually suffers a child, currently but also for his/her further personal development as future quality of life.

\section{Conclusions}

The occurrence of domestic violent behavior and its multiple consequences for the individual, family, and community should be seen from the health public approach and need for a proactive prevention strategies on first level of actions. As long as violent behavior patterns within family may be accepted as a private matter of its members, and its causes and effects on them, and more broadly on public health, will be overlooked, we could not expected any changes in this case. Therefore it is required to achieve that among adult persons in society the tolerance for all forms of violence, both in family as in a society, is at point zero. It is necessary to involves efforts (school, youth settings, work places), which reduce aggressive incidents in intimate relationship and family as a whole before they occur and focus on changing social attitudes, raising public awareness (media, politics, etc), and at the same time introduce a new values, thinking processes, and relationship skills which promote health interpersonal relationship and are incompatible with violence. It could be done also by collaborative efforts by school and communities and provide children and youth with information about local resources, and how to response to domestic violence situations. Only the criminal prosecutions against the perpetrators cannot reach the desired effects.

\section{References}

1. Walker LE. Psychology and domestic violence around the world. Am Psychol 1999;54:21-9.

2. Huss MT. Forensic psychology. Research, clinical practice, and applications. Singapore: Wiley-Blackwell; 2009.

3. Krug EG, Dahlberg LL, Mercy JA, et al, eds. Word report on violence and health. Geneva: Word Health Organisation; 2002.

4. Itzin C, Taket A, Barter-Godfrey S. Domestic and sexual violence and abuse. London, New York: Routledge; 2010.

5. Reid RJ, Bonomi AE, Rivara FP, et al. Intimate partner violence among men. Prevalence, chronicity and health effects. Am J Prev Med 2008;34:478-85.

6. Buzawa E, Buzawa CG. Domestic violence. 3th ed. Thousand Oaks: Sage Publications; 2003.

7. Sartin RM, Hansen DJ, Huss MT. Domestic violence treatment response and recidi- 
vism: A review and implications for the study of family violence. Aggress Violent Behav 2006;11:425-40.

8. HO. Crime in England and Wales 2007/8. London: HO; 2009.

9. Walker LE. The battered woman syndrome. New York: Springer; 1979.

10. Gondolf EW, Fisher ER. Battered women as survivors: an alternative to treating learned helplessness. Lexington: Lexington Books; 1988.

11. Gondolf EW. Service barriers for battered women with male partners in batterer programs. J Interpers Violence 2002;17:21727.

12. Dobash RE, Dobash RP. Violence against wives. New York: Free Press; 1979.

13. Dobash RE, Dobash RP, eds. Violent men and violent contex. In: Rethinking violence against women. Thousand Oaks, CA: Sage Publications; 1998. pp 141-168.

14. Hoffman KL, Edwards JN. an integrated theoretical model of sibling violence and abuse. J Fam Violence 2004;9:185-200.

15. Kurz D. Social science perspectives on wife abuse: current debates and future directions. Gender Soc 1989;3:489-505.

16. Sprey J. The family as a system of conflict. J Marriage Fam 1969;31:699-706.

17. Felson RB, Tedeschi JT, eds. Social interactionist perspectives on aggression and violence: an introduction. In: Aggression and violence: social interactionist perspectives. Washington: APA; 1993. pp 1-10.

18. Bandura A. Aggression: a social learning analysis. Eaglewood Cliffs: Prentice-Hall; 1973.

19. Bandura A. Social cognitive theory. In: Bryant J, Zillman D, eds. Media effects: advances in theory and research. $2^{\text {nd }}$ ed. Mahwah: Taylor and Francis Library; 2008. pp 121-154.

20. Pagelow MD. Family violence. New York: Praeger; 1984.

21. Loseke DR, Gelles RJ, Cavanaugh MM. Current controversies on family violence. 2nd ed. Thousand Oak: Sage Publications; 2005.

22. Moffitt TE, Caspi A, Rutter M, Silva PA. Sex differences in antisocial behaviour. Cambridge: Cambridge University Press; 2001.

23. Dutton DG, Bodnarchuk M. Through a psychological lens: personality disorder and spouse assault. In: Loseke D, Gelles R, Cavanaugh M, eds. Current controversies on family violence, 2nd ed. Thousand Oaks: Sage Publications; 2005. pp 5-18.

24. Carney MM, Buttell FP. A multidimension- al evaluation of a treatment program for female batterers: a pilot study. Res Social Work Prac 2004;1:249-58.

25. Henning K, Feder L. A comparison of men and women arrested for domestic violence: who presents the greater risk? J Fam Violence 2004;19:69-80.

26. Hart SD, Dutton DG, Newlove T. The prevalence of personality disorder among wife assaulters. J Pers Disord 1993;7:329-41.

27. Dutton DG, Hart SD. Risk factors for family violence in a federally incarcerated population. Int J Law Psychiat 1992; 5:101-12.

28. Dutton DG, Hart SD. Evidence of longterm, specific effects of childhood abuse and neglect on criminal behavior in men. Int J Offender Ther 1992;36:129-37.

29. Bancroft RL, Sillverman JG. Batterer as parent: addressing the impact of domestic violence on family dynamics. Thousand Oaks: SAGE Publications; 2012.

30. Bancroft RL. Why does he do that? New York: Penguin Group; 2002.

31. Dutton DG, White KR. Male victims of domestic violence. Available from: http://www.google.it/url?sa=t\&rct=j\&q=\& esrc $=s \&$ source $=$ web\&cd $=1 \& c a d=r j a \& u a c$ $\mathrm{t}=8 \&$ ved $=0$ CCYQFjAA\&url=http $\% 3 \mathrm{~A} \% 2 \mathrm{~F} \%$ 2Fnewmalestudies.com\%2FOJS\%2Findex. php\%2Fnms\%2Farticle\%2Fdownload\%2F5 9\%2F59\&ei=aFOmVPDULubGyg0V74DYC w\&usg=AFQjCNFXaKbtaTomyIdnlKsRE2d amXr7CA

32. Hines D, Douglas EM. Women's use of intimate partner violence against men: prevalence, implications, and consequences. J Aggress Maltreat Trauma 2009;18:572-86.

33. Williams SL, Frieze IH. Patterns of violent relationships, psychological distress, and marital satisfaction in a national sample of men and women. Sex Roles 2005;52:771-84.

34. Carney M, Buttel F, Dutton DG. Women who perpetrate intimate partner violence: a review of the literature with recommendation for treatment. Agress Violent Behav 2007;12:108-15.

35. Fontes DL. Male victims of domestic violence. In: Hamel J, Nicholls TL, eds. Family intervention in domestic violence. New York: Springer Publications; 2007. pp 303318.

36. Murrell AR, Christoff KA, Henning KR. Characteristics of domestic offenders: associations with childhood exposure to violence. J Fam Violence 2007;22:523-32.

37. Stith SM, Rosen KH, Middleton KA, et al. The intergenerational transmission of spouse abuse: a meta analysis. J Marriage
Fam 2000;62:640-54.

38. Cambell JC, Lewandowski LA. Mental health effects of intimate partner violence on women and children. Anger Aggression Violence 1997;20:353-74.

39. Cambell JC, Soekel KL. Women's responses to battering: a list of the model research. Nurs Health Sci 1999;22:49-58.

40. Campbell JC. Health consequences of intimate partner violence. Lancet 2002;359:1331-6.

41. Plichta SB. Violence, health and use of health services. In: Falik MM, Collins KS, eds. Women's health: health and care seeking behaviour. Baltimore: Johns Hopkins University Press; 1996. pp 237270.

42. Heise L, Garcia-Moreno C. Violence by intimate partners. In: Krug E, Dahlberg LL, Mercy JA, et al, eds. World report on violence and health. Geneva: World Health Organization; 2002. pp 87-121.

43. Leserman J, Drossman DA. Relationship of abuse history to functional gastrointestinal disorders and symptoms. Trauma Violence Abus 2007;8:331-43.

44. Coker A, Smith PH, Bethea L, et al. Physical health consequences of physical and psychologycal intimate partner violence. Arch Fam Med 2000;9:451-7.

45. Golding JM. Intimate partner violence as a risk factor for mental disorders: a meta analysis. J Fam Violence 1999;14:99-132.

46. Stark E, Flitcraft A. Violence between intimates: an epidemiological review. In: Van Hasselt VB, Morrison RL, Bellack AS, Hersen M, eds. Hand book of family violence. New York: Plenum Press; 1988. pp 293-317.

47. Aguilar RJ, Nightingale NN. The impact of specific battering experiences on the selfesteem of abused women. J Fam Violence 1994;9:35-45.

48. O'Leary KD. Psychological abuse: a variable deserving critical attention in domestic violence. Viol Victims 1999;14:3-23.

49. O'Leary KD, Maiuro RD. Psychological abuse in violent relations. New York: Springer Publications; 2001.

50. Follingsrad DR, Rutledge LL, Berg BJ, Hause ES. The role of emotional abuse in physically abusive relationships. J Fam Violence 1990;5:107-20.

51. Osofsky JD. The impact of violence on children. The future of children. Domest Viol Child 1999;9:33-49. 